\title{
Absorption of sodium and water by human rectum measured by a dialysis method
}

\author{
C. J. EDMONDS \\ From the MRC Department of Clinical Research, University College Hospital Medical School, \\ University Street, London
}

SUMMARY A dialysis method for the study of intestinal absorption is described. Its use has been assessed in animals and normal human subjects and it has been applied to the measurement of rectal transport of sodium and water.

When the luminal solution was of high sodium concentration (145 m-equiv/1), the sodium influx rate (lumen to plasma) was about five times greater than the sodium efflux rate (plasma to lumen). The luminal sodium concentration associated with zero net sodium flux was very low $(<15 \mathrm{~m}$-equiv/1). As the mucosa was charged with the luminal side negative, the epithelium must therefore possess a powerful sodium absorbing 'pump'. With isotonic solutions in the lumen, the amount of water absorbed depended on the sodium concentration and when this was $30 \mathrm{~m}$-equiv/1 or less, no significant water absorption was detectable. When, however, water absorption was altered by imposing osmotic gradients, sodium absorption was not significantly affected. The luminal solution tended to become issomolar with plasma; osmotic gradients across the epithelium did not develop.

The particular transport properties of rectal epithelium enabling it to remove sodium from the lumen against considerable electrochemical gradients are well adapted to its function.

To study absorption characteristics of intestine in conscious man, perfusion techniques have usually been employed. Among the disadvantages of these techniques is the need to perfuse a relatively long segment in order that the changes of composition produced are large enough to permit accurate measurements. Furthermore, if radionuclides are employed, there may be problems of radiation hazard due to absorption. The dialysis method described in the present paper was devised to overcome some of these difficulties. A tube made of a dialysis membrane and containing solution of a chosen composition is left in contact with the mucosa of an empty segment of intestine for a timed period. The transport properties of the epithelium at that region can then be deduced from changes in composition of the solution. A dialysis method was introduced some time ago by Wrong, Morrison, and Hurst (1961) in order to obtain samples of faecal fluid. Their method involved swallowing dialysis bags, followed by their subsequent recovery from faeces. The method had a different object from that of the present study and so could provide only Received for publication 11 March 1971. limited information on the behaviour of the epithelium at any specified region of the intestine. The object of the present work was to study the action of the epithelium at a particular site, and it was therefore most important that the region should be empty and not contaminated with intestinal contents from above or below.

The present report describes the results obtained by applying the technique to examination of the properties of rectal mucosa. Recently, Devroede and Phillips (1970), principally using perfusion methods, concluded that rectal mucosa failed to absorb electrolytes and water. The dialysis method shows clearly that this is not so and that the rectal epithelium absorbs water and possesses a powerful sodium absorbing mechanism capable of removing sodium from the lumen against considerable electrochemical gradients. ${ }^{1}$

\section{Methods}

Investigations were done on two healthy individuals

${ }^{1}$ A preliminary report on this work was given at meeting of the 356 
and eight patients who had no evidence of bowel disease. The age range of the subjects was 28 to 76 years. Apart from a few minutes necessary to make initial measurements, the subjects continued their ordinary activities during the period of observation. The nature of the procedure was explained to all the subjects. Several normal and sodiumdepleted rats, prepared as previously described (Edmonds, 1967), were also studied in preliminary trials.

\section{DIALYSIS TUBE}

The construction of the tube is shown in Figure 1. A segment of dialysis tube ${ }^{1}$ (diameter $0.5 \mathrm{~cm}$, length $8 \mathrm{~cm}$ ) was knotted at one end and passed over a rubber catheter (diameter $0.2 \mathrm{~cm}$ ) and secured by double tie over the rubber sleeve. In a few experiments, the rubber cannula contained an electrode made from polythene tubing filled with agar $4 \%$, $\mathrm{KCl} 3 \mathrm{M}$.

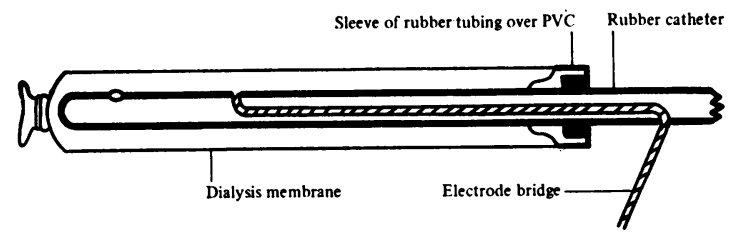

Fig. 1. The dialysis tube. The tube is shown containing an electrode bridge but for most experiments this was omitted.

\section{PROCEDURE}

The tube was filled using a $5 \mathrm{ml}$ syringe before the dialysis tube was tied. Air bubbles were expelled and the tube was tied in position, a glass spigot replacing the syringe. The tube was checked for leaks and weighed. It was inserted into the rectum at sigmoidoscopy on the first occasion but subsequently it was placed blindly after lubricating the tip with $\mathrm{KY}^{2}$ water-soluble jelly. The tube was inserted so that it was lying in the rectum with its base about $2 \mathrm{~cm}$ from the anus. The tube caused no discomfort and did not interfere with normal activities. It was removed by gentle traction, usually after one hour. Specimens or tubes showing faecal contamination were discarded. In some experiments, the rectum was subsequently rinsed twice with $20 \mathrm{ml}$ saline using a rubber catheter and syringe, the fluid being withdrawn and collected for measurement of radioactivity. In the animal studies, experiments were done on the descending colon, exposure and cannulation being as previously described (Edmonds, 1967). A $4 \mathrm{~cm}$-length of dialysis tube was used and

'Visking tubing 8/32.

'Johnson and Johnson Ltd, Slough. absorption measured both when solutions were in the tube (the distal cannula being removed for this purpose) and when solutions were placed for timed periods in the cannulated segment.

\section{MEASUREMENTS OF POTENTIAL DIFFERENCE}

Studies in man were done using probe and reference electrodes and a millivoltmeter of the type described by Edmonds and Cronquist (1970) except that $\mathrm{KCl} 3 \mathrm{M}$ was used instead of $\mathrm{NaCl} 150 \mathrm{mM}$ in the electrodes. The reference electrode was placed on abraded skin of the ventral surface of the forearm. The measurements were made at the end of the exposure period, $10 \mathrm{ml}$ of solution similar to that used in the tube being first injected into the rectum. In a few experiments, measurements were made using an electrode contained within the dialysis tube as shown in Figure 1. In the rats, measurements of potential difference were made as previously described (Edmonds, 1967).

CHEMICAL AND RADIONUCLIDE METHODS

Solutions placed in the tube were prepared from stock solutions of $\mathrm{NaCl} 150 \mathrm{mM}, \mathrm{KCl} 150 \mathrm{mM}$, and mannitol $500 \mathrm{mM}$. ${ }^{22}$ Sodium and ${ }^{42}$ Potassium were added to some solutions, the radionuclide content not exceeding a total of $5 \mathrm{nCi} / \mathrm{ml}$ except in a few animal experiments where up to $200 \mathrm{nCi} / \mathrm{ml}$ was used. Specimens collected were frozen for storage where analysis was delayed. Water loss was determined by weighing, sodium content measured by flame photometry, and osmolality by a Fiske osmometer. Changes of volume of the fluid within the tube were determined by weighing before and after each experiment. ${ }^{22}$ Sodium and ${ }^{42}$ Potassium were determined in $1 \mathrm{ml}$ samples using a well type $\mathrm{NaI}(\mathrm{Th})$ crystal scintillation counter; where both radionuclides were used, the samples were recounted after allowing several days for ${ }^{42}$ Potassium to decay. The content of ${ }^{42}$ Potassium in the colon mucosa of the rat was measured in vivo using a miniature Geiger counter (Barnaby and Edmonds, 1969).

\section{THEORY AND CALCULATIONS}

It is supposed that when the tube is in an empty segment of intestine it is surrounded by a thin layer of fluid which also lies in contact with the epithelium. Ions, water, and other substances can then diffuse from the fluid in the tube through the membrane and across the thin fluid layer, and are then transported across the epithelium into the blood. Flows of ions, water, and other substances will also occur in the opposite direction. In this system, the thin intermediate fluid layer is assumed to behave as a compartment of small capacity. Providing that the 
dialysis membrane is very permeable to the substance under investigation and the epithelium is considerably less permeable to it, the concentration of the substance in the intermediate fluid layer will rapidly approximate to its concentration in the tube. Once this steady state has been attained, the presence of the dialysis membrane can be ignored and the change in the amount of substance in the tube will depend on the rate at which it passes from the intermediate layer into the plasma. To measure the flux rates in the present experiments, ${ }^{22}$ Sodium was contained in the solutions in the tube and calculations were based on the assumption of one compartment (the luminal solution) and a large sink (the body), which seems to be adequate even for potassium calculations (Barnaby and Edmonds, 1969). Since changes of specific activity were relatively small, it was assumed that the fall with time was linear during exposure and accordingly the arithmetic mean was used in the calculations. Equations used were:

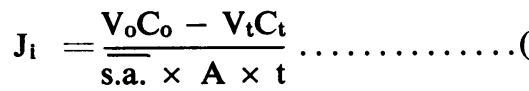

$$
\begin{aligned}
& \mathbf{J}_{\mathbf{n}}=\frac{\mathbf{V}_{\mathrm{o}} \mathbf{I}_{\mathrm{o}}-\mathrm{V}_{\mathrm{t}} \mathbf{I}_{\mathrm{t}}}{\mathbf{A} \times \mathrm{t}} \ldots \ldots \ldots \ldots \\
& \mathbf{J}_{\mathbf{o}}=\mathbf{J}_{\mathbf{n}}-\mathbf{J} \mathbf{i}
\end{aligned}
$$

where $J_{i}, J_{n}$, and $J_{o}$ are influx (lumen to plasma), net flux, and efflux (plasma to lumen) rates per min : $\mathrm{cm}^{2}$ respectively; $\mathrm{V}, \mathrm{C}$, and $\mathrm{I}$ are volume of tube fluid, radionuclide content $(\mathrm{cpm} / \mathrm{ml})$ and concentration of the ion; $\overline{\text { s.a. }}$., the mean specific activity; A, the surface area of the dialysis tube; and $t$, the time of exposure. The subscripts, $o$ and $t$, refer to initial and final values. The conventional sign usage is employed, influx (insorption) being positive and efflux (exsorption) being negative. All flux and absorption rates are in Terms of the area $\left(\mathrm{cm}^{2}\right)$ of the surface of the dialysis tube.

\section{Results}

ASSESSMENT OF THE METHOD

\begin{tabular}{|c|c|c|c|c|}
\hline & \multirow[t]{2}{*}{$\begin{array}{l}\text { Weight Loss } \\
\text { of Tube ( } \mathrm{mg})\end{array}$} & \multicolumn{2}{|c|}{$\begin{array}{l}\text { Concentrations ( } m \text { - } \\
\text { equiv/l) }\end{array}$} & \multirow[t]{2}{*}{$\begin{array}{l}\text { Potassium } \\
(\text { Cpm } / \mathrm{ml})\end{array}$} \\
\hline & & Sodium & Potassium & \\
\hline Initial solution & & 90 & 50 & 1,000 \\
\hline $\begin{array}{l}\text { After one hour } \\
\text { Subject } 1 \\
\text { Subject } 2\end{array}$ & $\begin{array}{l}0.21 \pm 0.05 \\
0.19 \pm 0.05\end{array}$ & $\begin{array}{l}61 \pm 8.5 \\
74 \pm 3.4\end{array}$ & $\begin{array}{l}53 \pm 3 \cdot 6 \\
48 \pm 4 \cdot 4\end{array}$ & $\begin{array}{l}340 \pm 20 \\
460 \pm 28\end{array}$ \\
\hline
\end{tabular}

A number of preliminary studies in norma subjects

Table I Consistency of changes in luminal solution during repeated periods of exposure of one hour of the dialysis tube in the rectum of two subjects (mean $\pm 1 S D)^{1}$

${ }^{1}$ Four observations were made in each subject. and in rats were carried out and the results will be briefly summarized. When a solution of the same composition was used several times during one day in two subjects, it was shown that the results were reproducible (Table I). The greatest variation was of weight change (SD $\pm 25 \%$ ) while the sodium and potassium concentrations had a standard deviation not greater than $\pm 15 \%$. For good consistency, it was, however, most important that the rectum was empty. The presence of faeces was obvious from brown staining of the tube fluid and such tubes were always discarded.

In experiments on rats, changes in composition of the luminal solution, whether placed freely in the lumen or within a dialysis bag, were examined. The results showed that the presence of the dialysis membrane had no significant effect on the magnitude of the changes observed (Table II). Also, both in rats and in human subjects, measurements of potential difference made by the electrode within the dialysis tube were compared with those made without the tube. In all instances, no significant differences were observed. The dialysis membrane does not, therefore, introduce artifacts into the

\begin{tabular}{|c|c|c|c|}
\hline & \multicolumn{2}{|c|}{ Concentrations (m-equiv/l) } & \multirow{2}{*}{$\begin{array}{l}\text { Sodium } \\
(\mathrm{Cpm} / \mathrm{ml})\end{array}$} \\
\hline & Sodium & Potassium & \\
\hline $\begin{array}{l}\text { Initial solution } \\
\text { After one hour }\end{array}$ & 30 & $\mathbf{0}$ & 1,000 \\
\hline $\begin{array}{l}\text { No tube } \\
\text { Solution within tube }\end{array}$ & $\begin{array}{l}29 \pm 0.8 \\
31 \pm 0.7\end{array}$ & $\begin{array}{l}1.4 \pm 0.1 \\
1.3 \pm 0.1\end{array}$ & $\begin{array}{l}515 \pm 11 \\
505 \pm 9\end{array}$ \\
\hline
\end{tabular}
measurements of potential difference.

Table II Comparison of changes in composition of a luminal solution in the rat descending colon.

${ }^{1}$ In some experiments the solution was free in the lumen and in others contained in dialysis tuce (mean \pm 1 SD). Results were obtained from two rats with a total of four observations in each case.

In some experiments, the changes in composition of the tube fluid were compared when the same solution was exposed with the tube in the rectum, in a stirred bath of saline, or in a flat, impermeable polythene bag. In the latter condition, the surface of the tube was in contact with the polythene. The ${ }^{22}$ Sodium content fell much less when the tube was in the rectum than when it was in a saline bath (Fig. 2) indicating that the sodium permeability of rectal mucosa was much less than that of the dialysis membrane, a necessary condition for the flux calculations. The weight loss was, however, much greater when the tube was in the rectum. No significant change was found when the tube was in the saline and only a very slight fall when it was in the polythene bag. In the latter case, at the end of 


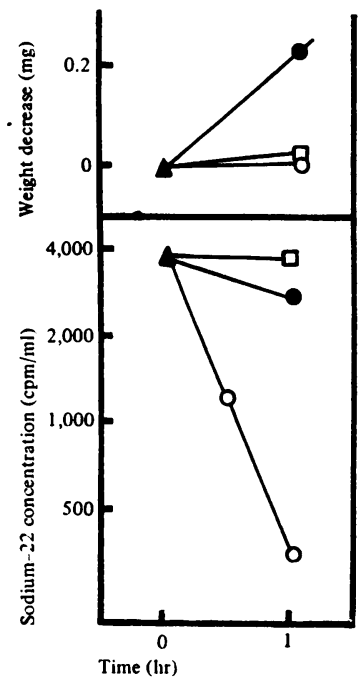

Fig. 2. Changes of weight and ${ }^{22}$ Sodium concentration of tube fluid $(\mathrm{NaCl} 145 \mathrm{mM})$ left for one hour under various conditions. The ${ }^{22}$ Sodium changes are plotted on a logarithmic scale. $=$ tube in rectum; $\bigcirc=$ tube in stirred saline bath; $\square=$ tube in $a$ polythene bag.

the hour, a thin film of fluid was evident over the area of contact of polythene and tube.

On four occasions after removal of the tube, following an hour's exposure, the rectum was rinsed twice with $10 \mathrm{ml}$ saline and the washings were collected and the radionuclide content was measured. The amount recovered from the lumen in this way was $5-9 \%$ of the total amount lost from the tube. Thus, during the exposure of an hour, at least $90 \%$ of that lost from the tube is absorbed.

Experiments on three rats were done to estimate the extent to which ions spread beyond the limits of the tube along the surface of mucosa. ${ }^{42}$ Potassium

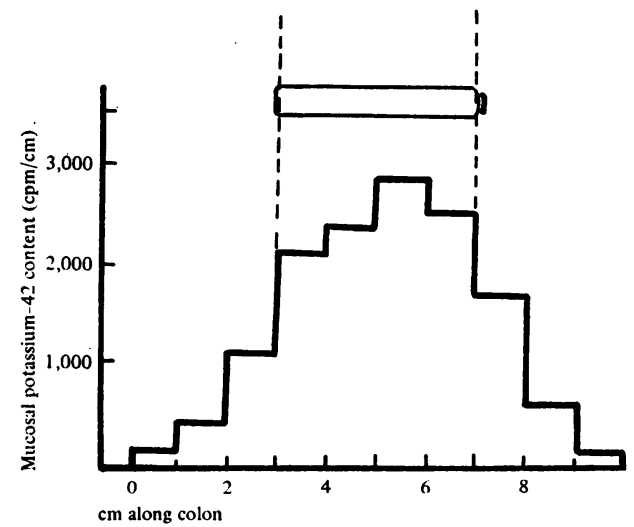

Fig. 3. ${ }^{42}$ Potassium content of mucosal epithelium of rat descending colon after exposure for one hour, the dialysis tube containing a saline solution and ${ }^{42}$ Potassium. Regions of colon beyond $1 \mathrm{~cm}$ from the end of the tube contained little ${ }^{12}$ Potassium. The position of the tube is shown. was added to the tube fluid since this is temporarily 'trapped' in the epithelial cells and can easily be measured (Barnaby and Edmonds, 1969), and so can act as a marker to indicate the spread. The ${ }^{42}$ Potassium content of the epithelium was maximal over the region where the epithelium was in direct contact with the tube (Fig. 3) and, although within 1 centimetre of the ends of the tube, the count rate was still about $50 \%$ of the maximal value; outside this limit the epithelium contained very little radioactivity. It seems likely, therefore, that nearly all the ionic movements between the luminal solution and the plasma take place through the epithelium in close contact with the tube surface.

\section{RECTAL TRANSPORT OF SODIUM AND WATER Sodium}

In studies in two subjects, a series of tests of exposure over one hour were done, each successive solution being prepared so as to have the same sodium concentration as that found at the end of the previous exposure. Both subjects showed similar changes and the changes in one of these are shown in Figure 4. Sodium concentration fell until it was

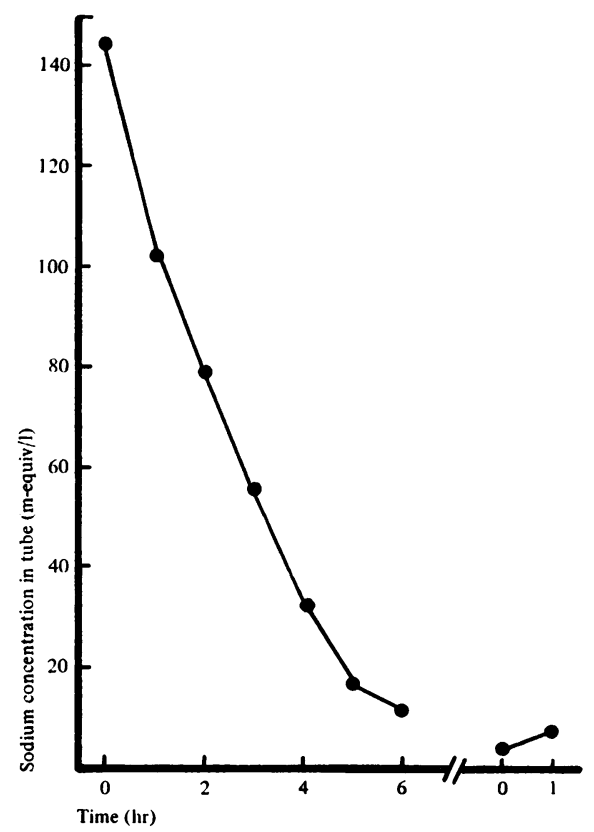

Fig. 4. Changes in sodium concentration of solutions in dialysis tubes during successive one-hour exposures. At the end of each exposure the final sodium concentration was determined and a solution of this concentration prepared (with mannitol added to ensure isotonicity) for the subsequent exposure. 
about 10 m-equiv/1. When, however, a solution of sodium concentration 3 m-equiv/ 1 was placed in the rectum, its sodium concentration rose. With solutions of higher sodium concentration, water absorption from the tube, as indicated by a fall in weight, always occurred but when the sodium concentration was very low, no absorption was detectable. In several subjects, a solution of $\mathrm{NaCl}$ $145 \mathrm{mM}, \mathrm{KCl} 5 \mathrm{mM}$ with ${ }^{22}$ Sodium added was used and the influx (lumen to plasma) determined (Table III). Although the content of ${ }^{22}$ Sodium fell in these experiments (Fig. 2), so also did the concentration of sodium so that changes of specific activity were insignificant. This indicated either that the net flux was zero or that it was relatively small compared with the influx so that when the amount of sodium present in the tube was high, the effect of the efflux was masked. Hence, in order to determine the sodium flux rates in most subjects, a solution of lower sodium concentration (30 m-equiv/1) was used (Table III). Even so, influx exceeded efflux so that in all subjects, the luminal sodium concentration fell during the exposure, the final value averaging $15 \mathrm{~m}$-equiv/1 (range 10 to 19 m-equiv/1). Thus, for the net sodium flux rate to be zero, the luminal sodium concentration must generally be about 15 m-equiv/1.

\begin{tabular}{|c|c|c|c|c|c|}
\hline $\begin{array}{l}\text { Initial } \\
\text { Sodium } \\
\text { Concentratio } \\
\text { (m-equiv/l) }\end{array}$ & $\begin{array}{l}\text { No. of } \\
\text { Subjects } \\
\text { n }\end{array}$ & $\begin{array}{l}\text { Influx } \\
\left(n-e^{2 q u i v /}\right. \\
\left.\mathrm{min} / \mathrm{cm}^{2}\right)\end{array}$ & $\begin{array}{l}\text { Efflux } \\
(n-e q u i v / \\
\left.\min / \mathrm{cm}^{2}\right)\end{array}$ & $\begin{array}{l}\text { Net Flux } \\
(n-e q u i v / \\
\left.\min / \mathrm{cm}^{2}\right)\end{array}$ & $\begin{array}{l}\text { Potential } \\
\text { Difference } \\
(m V)\end{array}$ \\
\hline $\begin{array}{r}145 \\
30\end{array}$ & $\begin{array}{l}4 \\
8\end{array}$ & $\begin{array}{r}112 \pm 23 \\
48 \pm 14\end{array}$ & $\overline{-24} \pm 9$ & $\begin{array}{l}112 \pm 23 \\
23 \pm 10\end{array}$ & $\begin{array}{l}-25 \\
(-19 \text { to } \\
\quad-32)\end{array}$ \\
\hline
\end{tabular}

Table III Sodium unidirectional flux rates measured in subjects with normal rectum (mean $\pm S D)^{1}$

${ }^{1}$ The negative sign on a flux rate indicates that the flow was directed towards the lumen. The higher and lower sodium concentration solutions were prepared with potassium concentrations of $5 \mathrm{~m}$-equiv/1 and $30 \mathrm{~m}$-equiv/l respectively. It was not possible to measure efflux rate when the luminal sodium concentration was $145 \mathrm{~m}$-equiv/l.

In one subject, the unidirectional flux rates were determined using a range of solutions of various sodium concentrations with ${ }^{22}$ Sodium; potassuim concentration was constant at 30 m-equiv/1 (Fig. 5). Estimating the net flux when luminal sodium concentration exceeded $50 \mathrm{~m}$-equiv $/ 1$ was unsatisfactory but the results obtained at lower concentrations suggested that the net flux did not vary significantly with increasing luminal sodium concentration. The influx increased linearly with increasing luminal sodium concentration over the range studied without any evidence of saturation kinetics. The potential difference measured at the time of the flux determinations (the luminal sodium concentration being

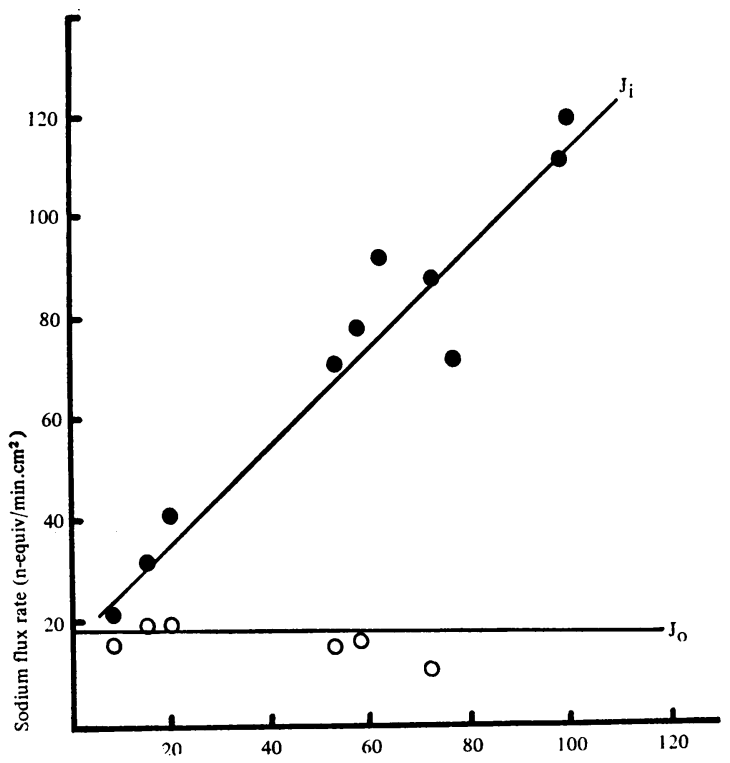

Fig. 5. Flux rates of sodium in a normal subject with solutions of various sodium concentrations in the lumen. Solutions were prepared with varying $\mathrm{NaCl}$ concentrations and constant $\mathrm{KCl}$ concentration at $30 \mathrm{mM}$ with mannitol added to make solutions isotonic. The values are plotted against the mean sodium concentration during the exposure. $=$ sodium influx rate $\left(J_{i}\right) ; \bigcirc=$ sodium efflux rate $\left(J_{0}\right)$.

about 30 m-equiv/1) averaged $-26 \mathrm{mV}$ (range -16 to $-33 \mathrm{mV}$ ). There was some dependence of potential difference upon sodium concentration but the effect was small; for example, in one subject the potential difference averaged $-24 \mathrm{mV}$ with $150 \mathrm{mM} \mathrm{NaCl}$ in the tube and $-19 \mathrm{mV}$ when it contained $10 \mathrm{mM} \mathrm{NaCl}$. These small changes of potential difference are of similar magnitude to those observed by Dalmark (1970) when the sodium concentration of solutions placed in the rectum was reduced.

\section{Water}

When the luminal solution had an initial sodium concentration of 145 m-equiv/1, the average weight loss of the tube was $0.22 \pm 0.04 \mathrm{~g}$ (four subjects, mean $\pm \mathrm{SD}$ ) corresponding to an average water absorption rate of $0.24 \mu \mathrm{l} / \mathrm{min} / \mathrm{cm}^{2}$. When the luminal solution had a low sodium concentration (initially $30 \mathrm{~m}$-equiv/1) the average weight loss was much less at $0.05 \pm 0.04 \mathrm{~g}$ (eight subjects, mean \pm SD), a value not significantly different from zero. In one subject, a number of exposures using solutions of high or low sodium concentration were carried 


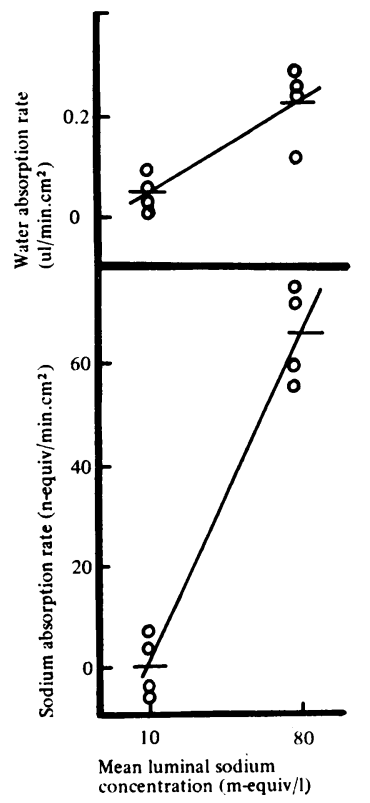

Fig. 6. a Effect of altering sodium concentration of the luminal solution on the absorption rates of water and sodium. The solutions were prepared with constant potassium concentration (30 m-equiv/1) and isotonicity was maintained by the addition of mannitol. Note that the increased sodium absorption resulting from the higher luminal sodium concentration is associated with increased water absorption.

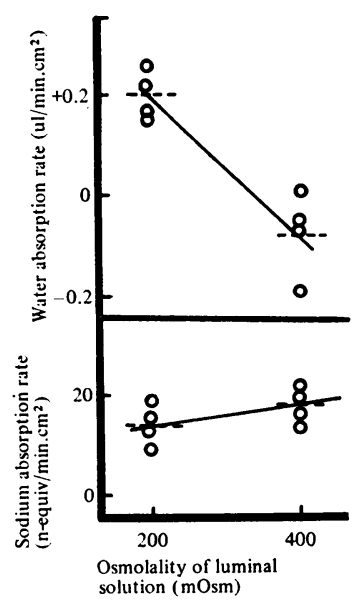

b Effect of altering water activity upon the absorption rates of water and sodium. Water activity was varied by changing the osmolality of the luminal solution by the addition of mannitol. Note that change of water flow rate did not influence sodium absorption rate. out, all solutions being made isotonic by addition of mannitol, and the results clearly confirmed those above in showing that water absorption rate was greater when luminal sodium concentration and sodium absorption rate were higher (Fig. 6a). To see whether changes in the rate of water flow affected sodium absorption, hypotonic and hypertonic solutions having similar sodium concentrations were used. Thus water activity was varied but electrolyte activity was not. This resulted in considerable change in net water movement from absorption to secretion but sodium absorption was unaffected (Fig. 6b). These results are consistent with the view that water absorption from isotonic solutions by the rectum depends on active absorption of sodium probably by development of local osmotic gradients within the tissue as suggested for other epithelia (Curran and McIntosh, 1962; Diamond and Bossert, 1967).

In several of the experiments in which isotonic solutions of various sodium concentrations were used, the osmolalities were determined after exposure. The average osmolality was $298 \pm 12 \mathrm{mOsm}$ (16 observations, mean \pm SD) which did not significantly differ from the initial value. Also, when in some trials hypotonic solutions (about 200 mOsm) were used, the osmolality was invariably greater at the end of one hour exposure (average value 242 mOsm, five experiments) while if the solution was initially hypertonic (about $400 \mathrm{mOsm}$ ), the osmolality fell (average final value $354 \mathrm{mOsm}$, three experiments). The potential difference was not significantly affected by changes in osmolality of the luminal solution.

There was no evidence in these experiments that significant osmotic gradients could develop across the rectal epithelium and therefore when sodium concentration fell, its place must have been taken by other substances. Potassium appears to be one of those which replaces sodium but others may also be secreted into the lumen.

\section{Discussion}

Several of the assumptions in the theory of the dialysis method which were tested in the preliminary assessment appeared to be true. For example, the model experiment with the tube in a polythene bag demonstrated the thin fluid layer that was present between the tube and an adjacent membrane. The weight loss of the tube in this experiment indicated the small volume of the layer, an observation consistent with the finding that little radioactivity was recoverable from the rectal lumen after an exposure. The animal experiments indicated that the presence of the dialysis membrane made little difference to the estimate of ionic movements and potential difference, and also that nearly all the movements from the tube to the animal took place over the area of contact. Thus, in expressing the results in relation to the area of the tube surface, they should approximate to the area $\left(\mathrm{cm}^{2}\right)$ of mucosal surface. The principal advantage of the present technique is that a short defined segment of intestine can be studied by a sensitive method. Although the rectum is the most obvious and easy segment to investigate, because it is accessible and usually empty, with some modifications possibly other parts 
of intestine could also be examined. The method is sensitive because small volumes of solution can be held at a chosen site for fairly long periods, a procedure which is otherwise not practicable in conscious man. Furthermore, it is an advantage that if radioactive tracers are used, very little activity is absorbed.

The particular sensitivity of the dialysis method is demonstrated by the results of the rectal studies. Employing perfusion methods, Devroede and Phillips (1970) were unable to show significant sodium or water absorption and concluded that, in contrast with the rest of the colon, the rectum 'failed to absorb water and electrolytes'. This result was surprising as rectal mucosa is electrically polarized like the rest of the colon (Geall, Spencer, and Phillips, 1969; Dalmark, 1970) and the potential difference rises considerably when aldosterone or other mineralocorticoids are administered (Edmonds and Godfrey, 1970). Similar changes in rat colon are associated with increased sodium absorption (Edmonds and Marriott, 1967) so that the rise of potential difference in man suggested the presence of a sodium absorptive mechanism in rectal mucosa. The dialysis method gave results consistent with this suggestion demonstrating clearly that rectal mucosa is not inert in regard to the transport of ions but can remove sodium from the lumen against considerable electrical and sodium concentration gradients. The epithelium must, therefore, possess a highly efficient active sodium transport mechanism.

It is difficult to make satisfactory comparisons with absolute flux rates obtained by perfusing the whole colon. Nevertheless, the present results are of similar order to those obtained by perfusion studies, although showing some differences. Thus Shields (1966) measured flux rates using a luminal solution (Tyrode's) with sodium and potassium concentrations of about 150 and 5 m-equiv/1 respectively. If for approximate comparison they are expressed in $\mathrm{cm}^{2}$, the colon being treated as a tube $150 \mathrm{~cm}$ long and of $4 \mathrm{~cm}$ in diameter, the average values obtained for sodium were: influx $=338$, efflux $=151$, expressed in n-equiv $/ \mathrm{min} / \mathrm{cm}^{2}$. The present results obtained with a solution of similar sodium concentration in the rectum gave a value for influx of only $112 \mathrm{n}$-equiv $/ \mathrm{min} / \mathrm{cm}^{2}$, considerably less than for the colon as a whole. Furthermore, if the relative values of efflux and influx are considered, a striking difference is evident. For whole colon, the efflux had a value of about $45 \%$ of the influx, but for the rectum efflux was only about $20 \%$ of influx (assuming the value of efflux shown in Table III). Sodium efflux is probably passive and these findings, therefore, strongly suggest that permeability to passive sodium movement is considerably less for rectal epithelium than for that of other parts of the colon.

The characteristics of colonic epithelium probably differ in various regions. For example, the response to aldosterone is much greater in the distal than in the proximal colon (Edmonds and Marriott, 1967). It would be expected that the variations reflect functional requirements. An important function of distal colon and rectum is sodium conservation and sodium has to be removed against considerable electrochemical gradients as here the faecal fluid has low sodium concentration. The present results, indicating the restricted permeability of rectal mucosa to passive ionic diffusion together with the presence in the epithelium of a powerful sodium absorbing 'pump' would seem well suited to the functional requirements of this region of intestine.

\section{References}

Barnaby, C. F., and Edmonds, C. J. (1969). Use of a miniature G.M. counter and a whole body counter in the study of potassium transport by the colon of normal, sodium-depleted and adrenalectomized rats in vivo. J. Physiol. (Lond.), 205, 647-665.

Curran, P. F., and McIntosh, J. R. (1962). A model system for biological water transport. Nature (Lond.), 193, 347-348.

Dalmark, M. (1970). The transmucosal electrical potential difference across the human rectum in vivo following perfusion of different electrolyte solutions. Scand. J. Gastroent., 5, 421-426.

Devroede, G. J., and Phillips, S. F. (1970). Failure of the human rectum to absorb electrolytes and water. Gut, 11, 438-442.

Diamond, J. M., and Bossert, W. H. (1967). Standing-gradient osmotic flow. J. gen. Physiol., 50, 2061-2083.

Edmonds, C. J. (1967). Transport of sodium and secretion of potassium and bicarbonate by the colon of normal and sodium and depleted rats. J. Physiol. (Lond.), 193, 589-602.

Edmonds, C. J., and Cronquist, A. (1970). A simple millivoltmeter and electrodes for measurement of rectal electrical potential in man. Med. biol. Engng., 8, 409-410.

Edmonds, C. J., and Godfrey, R.C. (1970). Measurement of electrical potentials of the human rectum and pelvic colon in normal and aldosterone-treated patients. Gut, 11, 330-337.

Edmonds, C. J., and Marriott, J. C. (1967). The effect of aldosterone and adrenalectomy on the electrical potential difference of rat colon and on the transport of sodium, potassium, chloride bicarbonate. J. Endocr., 39, 517-531.

Geall, M. G., Spencer, R. J., and Phillips, S. F. (1969). Transmucosal electrical potential difference of the human colon. Gut, 10, 921-923.

Shields, R. (1966). Absorption and secretion of electrolytes and water by the human colon, with particular reference to benign adenoma and papilloma. Brit. J. Surg., 53, 893-897.

Wrong, O., Morrison, R. B. I., and Hurst, P. E. (1961). A method of obtaining faecal fluid by in-vivo dialysis. Lancet, 1, 1208-1209. 